\title{
The COVID-19 pandemic and its effect on Otolaryngology trainees: A comprehensive nationwide cross-sectional study.
}

\author{
Salma S. Al Sharhan ( $\sim$ Ssalsharhan@iau.edu.sa) \\ Immam Abdulrahman bin Faisal University \\ Mohammed H. Al Bar \\ Immam Abdulrahman bin Faisal University \\ Abdulmalik S. AlSaied \\ Immam Abdulrahman bin Faisal University \\ Abdulaziz S. ALEnazi \\ Immam Abdulrahman bin Faisal University \\ Hussain J. Aljubran \\ Immam Abdulrahman bin Faisal University \\ Saud K. AlKhaldi \\ Immam Abdulrahman bin Faisal University \\ Amal A. Alghamdi \\ Immam Abdulrahman bin Faisal University
}

\section{Research Article}

Keywords: COVID-19, residents, otolaryngology residents, impact

Posted Date: September 21st, 2020

DOI: https://doi.org/10.21203/rs.3.rs-81574/v1

License: (c) (i) This work is licensed under a Creative Commons Attribution 4.0 International License. Read Full License 


\section{Abstract}

Background: As a consequence of the COVID-19 global pandemic, otolaryngology residents are at high risk due to the nature of the specialty and long work hours. Moreover, COVID-19 could have a severe impact on residents from different frontline specialties, particularly otolaryngology. To the best of our knowledge, this is the first nationwide survey providing insights into the impact of COVID-19 on otolaryngology residents.

Methods: A cross-sectional questionnaire-based study was conducted among all otolaryngology training centers of Saudi Arabia to investigate the extent of the impact of COVID-19 on otolaryngology residents and the learning process.

Results: A total of 152 residents were contacted to participate in the study, and 101 participants were included after successfully completing the questionnaire. The mean age of the participants was 28.12 years (S.D. $=1.89, \max =36, \mathrm{~min}=25$ ). There has been a significant impact on outpatient clinics, elective operations, consultations, and working hours. Also, we evaluated the impact on academic training activities, the frequency of training activities per week, and the psychological impact of the COVID-19 pandemic on otolaryngology residents as well.

Conclusion: COVID-19 has had a serious impact on residents both physically and mentally; otolaryngology residents have been hit especially hard by this emergency pandemic period. Trainees suffered from excessive worries regarding clinical training, specifically academic concerns for different training levels. Further studies need to be done here in Saudi Arabia to evaluate this impact in greater detail and to protect the residents.

\section{Introduction}

Coronavirus disease (COVID-19) first appeared then spread rapidly in Wuhan City, China and was identified on December 31, 2019 as a highly contagious disease that affects the respiratory system. ${ }^{1}$ On January 30,2020 , the World Health Organization (WHO) declared the situation a public health emergency of international concern. In Saudi Arabia, more than 76,000 reported cases and 411 deaths had been announced by May 27, 2020. This was in addition to the surge of confirmed COVID-19 cases in Saudi Arabia and a subsequent stay-at-home policy implemented in many regions, which affected many people of different demographics and professions. Notably, the COVID-19 outbreak undoubtedly interrupted residency training programs in general, including the otolaryngology residency program. The Saudi Board program of Otolaryngology Head \& Neck Surgery is a five-year residency training program, offering a unique educational experience that provides exposure to all facets of otolaryngology. Overall, due to this pandemic emergency, many health practitioners are at high risk. However, otolaryngology residents are at even higher jeopardy, which has been classified in the very-high-risk category because of the potential of exposure to coronavirus through aerosol-generating procedures. ${ }^{2}$ Hence, it is necessary to reduce the risk of this outbreak by minimizing residents' close contact with suspected COVID-19 patients. However, such exposure can distract residents and negatively impact their performance. ${ }^{3,4}$

Because of the contagious nature of the disease, the board members of the Saudi Commission for Health Specialties (SCFHS) have discussed changes, raised national alert levels, and implemented wide-range measures to minimize the risk for trainee residents. It is worth mentioning that the impact of COVID-19 on residents extends beyond infection to possibly negatively impact residents' mental health and developmental and learning processes.

This study explores the nature and extent of this impact on trainee residents in their workplace. Likewise, the article discusses the current challenges and offers some simple strategies to bridge the gaps in trainee residents' education to overcome this crisis.

\section{Methods}

We conducted a cross-sectional questionnaire-based study targeting all otolaryngology residents in Saudi Arabia to evaluate the degree to which COVID-19 affected them physically and mentally and to evaluate their general knowledge about the disease, having first obtained institutional board review approval (IRB -2020-01-129) from the Imam Abdulrahman bin Faisal University Ethical Review Committee. An online survey was specifically designed for this study and sent to all otolaryngology residents of the SCFHS through text messages in 4 regions of Saudi Arabia (Eastern, Western, Middle, Southern) over a period of 3 weeks from May 18, 2020 to June 8, 2020, followed by reminder messages sent 3 times with a 5-day gap. The principal study consisted of 44 questions written in English, which comprised 2 thematic blocks. The first 21 questions queried the residents' sociodemographic data, including age, gender, marital status, training level (ranging from R1 to R5), center of training, region, and practice as routine involvement in a clinical practice relevant to the pandemic. The second consisted of 23 questions and comprised 4 sections. The first section evaluated the residents' knowledge about the COVID-19 pandemic measured using a percentage scale that ranged from 0 to 100 . The evaluation of the residents' concern about the pandemic was in the second section and was measured using a numeric slider that determined the percentage of their concern ( 0 to 100). The third section screened the magnitude of anxiety using the screening tool of the Generalized Anxiety Disorder-7 (GAD-7) ${ }^{5}$ The final section evaluated the residents' attitudes toward COVID-19 using a percentage scale ranging from 0 to 100 .

The analyses were done using Stata software version 16. Student's t-test and one-way analysis of variance (ANOVA) test were used to examine the difference in the items' scores among our study subgroups, as appropriate. In addition, a chi-squared test was used to examine the differences in the distribution of the study variables among the study subgroups. 


\section{Results}

\section{Included participants and their sociodemographic features}

We were able to approach 152 out of the 211 otolaryngology residents in Saudi Arabia. After excluding any incomplete data, 101 participants were included, giving a completion rate of $65.58 \%$. Table 1 summarizes the sociodemographic features of the participants and their academic indicators. The mean age of the participants was 28.12 years $(S D=1.89, \max =36, \min =25)$. In addition, the majority of the trainees who sacrificed their otolaryngology training covering frontline duties were receiving their training in secondary hospitals $(56.67 \%, n=17)$, and they were in the junior training level $(63.33 \%, \mathrm{n}=19 ; \mathrm{R} 1=6, \mathrm{R} 2=13)$.

\section{The impact of the COVID-19 pandemic on academic activities}

The majority of training activities were continued despite the presence of the pandemic $(59.4 \%, n=60)$. However, the COVID-19 pandemic was found to have a statistically significantly large impact on the number of covered outpatient clinics, elective operations, consultations, and working hours. At the same time, the COVID-19 pandemic did not statistically significantly affect the number of homes on-calls (for further details, see Table 2). Around $36.63 \%(n=37)$ of participants went under quarantine, which lasted on average for 15.24 days $(S D=11.72, \min =1, \max =60)$ as $29.70 \%(n=30)$ worked in COVID-19 pandemic frontline defense either to cover the ICU $(20.00 \%, n=6)$ or by performing otolaryngology-related procedures (such as taking nasal swabs, laryngoscopy, or airway intubation; $26.67 \%, n=8)$, assisting in the emergency room department $(16.67, n=5)$, as well as doing paperwork duties to support other medical specialty physicians. As an alternative to traditional clinics and face-to-face consultation, around $63.37 \%$ $(n=64)$ of otolaryngology residents used telemedicine either through texting applications such as WhatsApp, emails, or other social media applications $(37.50 \%, n=24)$, through performing video calls using applications such as Zoom, Skype, or others $(9.38 \%, n=6)$, or through using audio calls such as phone calls or other audio applications $(53.13 \%, n=34)$. However, as seen in Table 3 , other than using telemedicine for consultations, many training programs were not affected by the pandemic, as a minority of trainees were pulled out of their otolaryngology training activities to fight against the COVID-19 pandemic.

\section{Attitudes of residents toward their training activities during the COVID-19 pandemic}

Table 4 summarizes the central tendency statistics of trainees' attitude items' scores ( 0 to 100$)$ toward their academic training according to their academic level. In general, R5 level residents were found to have the highest satisfaction mean scores toward their training activities. Nevertheless, regarding the training center level, participants who were trained in a tertiary hospital reported a significantly higher satisfaction toward their selfdevelopment during COVID-19 (mean $=55.16, S D=29.23, F=3.20, p=0.046)$ compared to university hospital trainees $($ mean $=43.52, S D=29.23)$ and secondary hospital trainees' (mean $=43.63, S D=21.30$ ) satisfaction levels. These results are due to the fact that tertiary hospitals tend to provide residents with a high-quality level of education experience and clinical training. Furthermore, training is aided by the expertise of physcians who are present more often in tertiary hospitals compared to other hospitals.

\section{The psychological impact of the COVID-19 pandemic on otolaryngology residents}

As shown in Table 5, around half of the otolaryngology trainees suffered from excessive worries $(54.46 \%, n=55)$. However, these worries (in the majority) were not excessive in terms of their intensity, frequency, or ability to control them. Furthermore, there was no difference between trainees who covered the frontline service against the pandemic and trainees who remained at their duties in regard to the severity or the characteristics of these worries. In contrast, Table 6 specifically provides insight into the academic concerns and worries in relation to the training level. As seen there, the highest level of concern was experienced in regard to the absence of a clear training rotation plan ( $m e a n=67.02, S D=30.99)$; however, there were no differences between the trainees in regard to the type of their concerns except regarding the absence of personal experience in such a pandemic situation as R3 trainees statistically significantly showed the lowest levels of concern.

\section{Discussion}

The COVID-19 outbreak is an unprecedented challenge with ripple impacts throughout health care systems globally. During this study, conducted during the peak of the pandemic in Saudi Arabia, we sought to determine how COVID-19 has disrupted the practice of otolaryngology residency training programs and affected trainee residents' learning curve, especially in clinical and surgical skills.

To the best of our knowledge, this is the first nationwide survey providing insights into the impact of COVID-19 on otolaryngology residency training programs, which have been hard hit by the emergency pandemic period. In this study, participants reported a large magnitude in Cohen's d effect size in some of their training activities, such as outpatient clinics, elective operations, consultations, and their working hours. These significant deficiencies have to be considered to ensure that the residents are given the optimum qualified training that they require.

Among physicians, otolaryngologists have been one of the most affected groups during this global pandemic. Moreover, they have been recorded as having the highest proportion of contagion spread due to the nature of their work as they have the closest contact with the upper respiratory tract mucosa where the high viral load exists..$^{6-9}$ In addition, patients with COVID-19 may present with symptoms mimicking those that appear in patients who are seeking medical advice about the ear, nose, and throat (ENT) region, which also puts otolaryngologists at high risk compared to other 
specialties. ${ }^{9}$ Accordingly, urgent measures were implemented in order to minimize the transmission of COVID-19 in health care settings, which included reducing specialist clinics, outpatient procedures, and the use of operating theatres. In response, telemedicine has been implemented in the majority of hospitals, allowing face-to-face consultations to be cancelled and replaced by telephone consultations and virtual clinics. Moreover, all non-urgent cases should have been postponed, as per the European Rhinology Society's recommendations, as should all elective surgery cases that did not require immediate intervention, with priority reserved for oncology and obstructive airway cases. ${ }^{10}$ Likewise, outpatient procedures were stratified by urgency. Importantly, in such cases, crucial personal protective equipment (PPE), such as N95 masks, fluid resistant gloves and gowns, goggles/face shields must be worn. Furthermore, adequate PPE should be provided by hospitals to handle this crisis, with all trainee residents trained in the proper usage of this equipment. Taken together, these precautions will maximize the residents' protection from the COVID-19 risks, including the physical and psychological aspects. ${ }^{11}$ At the same time, this will affect the practice of residents as well as their mental health, as elective cases have been suspended and residency examinations delayed, which will surely have a stressful impact on training residents. ${ }^{12}$

Despite all those issues residents were facing because of this pandemic, the training residency program continued. For this reason, Saudi board program members have discussed changes to national health care systems and the impact on otolaryngology residents to initiate a new plan for their residents in response to the COVID-19 pandemic to ensure their safety and provide maximum clinical practice. ${ }^{13}$

A slowdown of the learning curve for residents was inevitable, so residency teaching switched to online learning and attempts to maintain training were applied through online smart-learning circuits, webinars, and video calls. Based on the different central tendency statistics of trainees' attitudes' item scores, our study reported satisfaction with the residents' academic development among the different resident levels. In general, R5 level residents were found to have the highest satisfaction mean scores toward their training activities, which can be explained by their seniority and years of experience.

In addition to the activities and attitude effects, as a new disease with limited information about its characteristics, COVID-19 has had a significant impact on residents' physical and mental health. ${ }^{14}$ Currently, few studies have been conducted on mental health among residents during this crisis. In our study, we used GAD-7 scores to measure otolaryngology residents' anxiety; we found that around half of the residents were understandably anxious. However, their anxiety was not immoderate in terms of its intensity, frequency, or ability to control it. Overall, there was no difference between trainees who covered the frontline service against the pandemic or trainees who remained in their duties with regard to the severity or the characteristics of these worries. Yet, the current pandemic and changes in work plans will no doubt contribute to residents' burnout. ${ }^{15}$ During the crisis, it is important to offer psychological counseling for trainees to cope with the situation. ${ }^{16}$

Residency training programs are facing the same crisis with an overall reduction in their activities and increase in stress and concerns. It was clear from our results that the highest concern level is the absence of a clear training rotation plan because of the unexpected appearance of this pandemic. Nevertheless, there were no differences in the other types of concern except in that of personal experience, which showed a high level in some training levels, such as R2 and R4, while R3 and R5 residents showed a low level of concern, which was controversial. Although we have dedicated our careers to otolaryngology surgery, in times of need, otolaryngologists have played a role in serving society and public health.

As with all studies involving surveys from volunteers, selection bias is hard to avoid and may not necessarily represent the majority opinions of every trainee resident around the world. To help overcome these limitations, private social media networks were utilized specifically targeting

otolaryngology residents to participate in the surveys. Other drawbacks include the absence of objective indicators, for example, log books and details about surgical skills, as otolaryngology is a surgical specialty. Accordingly, further studies are needed to elucidate the effects of other variable factors.

\section{Conclusion}

COVID-19 has had a serious impact on residents, whether it affects their learning process, attitude, practice, or mental health, especially otolaryngology residents due to the nature of the specialty. Further studies need to be done here in Saudi Arabia to evaluate this impact in greater detail and among different specialties in order to protect residents.

\section{Declarations}

\section{Ethics approval and consent to participate:}

Ethical approval was granted by the Imam Abdulrahman bin Faisal University Ethical Review Committee (IRB -2020-01-129) and all participants gave informed consent.

\section{Consent for publication:}

N/A

\section{Availability of data and materials:}

The dataset used and analysed during the current study are available from the corresponding author on reasonable request. 
Authors contribution:

SSA contributed to idea conception, wrote and revised the manuscript. MHA, ASA, ASA revieved the literature and participate in writing and reviewing the manuscript. HJA, SKA participate in data collection and writing and revising the manuscript. AAA compiled and analyzed the data and participate in writing the manuscript. All authors read and approve the final manuscript.

\section{Funding:}

This study did not have any specific grant from public or private sectors.

\section{Competing interests:}

None declared.

Acknowledgments:

Thanks to our colleagues at Otolaryngology Department and Epidemiology division of Family Medicine Department in King Fahad Hospital of University for their constructive contributions. Also, we are grateful to our residents for their understanding and agreement to participate in the study.

\section{Abbreviations}

COVID-19: Coronavirus disease 2019; GAD-7: Generalized Anxiety Disorder-7; PPE: Personal protective equipment.

\section{References}

1. Zhang Y, Ma ZF. Impact of the COVID-19 Pandemic on Mental Health and Quality of Life among Local Residents in Liaoning Province, China: A Cross-Sectional Study. Int J Environ Res Public Health [Internet]. MDPI AG; 2020 Mar 31;17(7):2381. Available at: https://doi.org/10.3390/ijerph17072381

2. US Department of Labor, Occupational Safety and Health Administration. Guidance on preparing workplaces for COVID-19. 0SHA 3990-03 2020. Accessed Apr 18, 2020.

3. Vargo E, Ali M, Henry F, Kmetz D, Krishnan J, Bologna R. Cleveland Clinic Akron General Urology Residency Program's COVID-19 Experience [Internet]. 2020. Available at: https://doi.org/10.1016/j.urology.2020.04.001

4. Crosby DL, Sharma A. Insights on Otolaryngology Residency Training during the COVID-19 Pandemic. Otolaryng Head Neck. 2020 Apr 21:0194599820922502. Available at: https://doi.org/10.1177/0194599820922502

5. Screening for Generalized Anxiety Disorder (GAD) | Anxiety and Depression Association of America, ADAA. Accessed Aug 1, 2020.

6. Vukkadala N, Qian ZJ, Holsinger FC, Patel ZM, Rosenthal E. COVID-19 and the Otolaryngologist: Preliminary Evidence-Based Review. Laryngoscope. 2020 Mar 26. Available at: https://doi.org/10.1002/lary.28672

7. Lu D, Wang H, Yu R, Yang H, Zhao Y. Integrated infection control strategy to minimize nosocomial infection of coronavirus disease 2019 among ENT healthcare workers. $J$ Hosp Infect. 2020 Apr;104(4):454. Available at: 1016/j.jhin.2020.02.018

8. Zou L, Ruan F, Huang M, Liang L, Huang H, Hong Z, Yu J, Kang M, Song Y, Xia J, Guo Q. SARS-CoV-2 Viral Load in Upper Respiratory Specimens of Infected Patients. N Engl J Med. 2020 Mar 19;382(12):1177-9. Available at: 1056/NEJMc2001737

9. Kowalski LP, Sanabria A, Ridge JA, Ng WT, de Bree R, Rinaldo A, Takes RP, Mäkitie AA, Carvalho AL, Bradford CR, Paleri V. COVID-19 pandemic: Effects and evidence-based recommendations for otolaryngology and head and neck surgery practice. HEAD NECK-J SCI SPEC. 2020 Jun;42(6):1259-67. Available at: https://doi.org/10.1002/hed.26164

10. Website of the ERS (n.d.). Accessed July 26, 2020.

11. World Health Organization. Rational use of personal protective equipment (PPE) for coronavirus disease (COVID-19): interim guidance, 19 March 2020. World Health Organization; 2020. Accessed July 29, 2020.

12. Balhareth A, AIDuhileb M, Aldulaijan F, Aldossary M. Impact of COVID-19 pandemic on residency and fellowship training programs in Saudi Arabia: A nationwide cross-sectional study. Ann Med Sur. 2020 Sept;57:127-132. Available at: https://doi.org/10.1016/j.amsu.2020.07.025

13. Moazzami, B, Razavi-Khorasani, N, Moghadam, A D, Farokhi, E, \& Rezaei, N (2020). COVID-19 and telemedicine: Immediate action required for maintaining healthcare providers well-being. J Clin Virol, 126, 104345. Available at: https://doi.org/10.1016/j.jcv.2020.104345

14. Yin X, Wang J, Feng J, Chen Z, Jiang N, Wu J, Yan S, Li H, Lv C, Lu Z, Gong Y. The Impact of the Corona Virus Disease 2019 Outbreak on Chinese Residents' Mental Health. 2020 Mar 14. Available at: https://dx.doi.org/10.2139/ssrn.3556680

15. Marchalik D, Goldman CC, Carvalho FFL, et al. Resident burnout in USA and European urology residents: an international concern. BJU Int 2019;124:349-56. Available at: https://doi.org/10.1111/bju.14774

16. Wong JG, Cheung EP, Cheung V, et al. Psychological responses to the SARS outbreak in healthcare students in Hong Kong. Med Teach. 2004;26(7):657-659. Avaialble at: https://doi.org/10.1080/01421590400006572

Page $5 / 9$ 


\section{Tables}

Table 1 Distribution of sociodemographic features of the study participants $(n=101)$

\begin{tabular}{|c|c|c|}
\hline & Frequency & Percent \\
\hline & $N=101$ & $\%$ \\
\hline \multicolumn{3}{|l|}{ Age } \\
\hline$<=25$ years & 6 & 5.94 \\
\hline$\varnothing 25$ and $<=30$ years & 89 & 88.12 \\
\hline$>30$ and $<=35$ years & 5 & 4.95 \\
\hline > 35 years & 1 & 0.99 \\
\hline \multicolumn{3}{|l|}{ Gender } \\
\hline Male & 55 & 54.46 \\
\hline Female & 46 & 45.54 \\
\hline \multicolumn{3}{|l|}{ Marital status } \\
\hline Single & 68 & 67.33 \\
\hline Married & 33 & 32.67 \\
\hline \multicolumn{3}{|l|}{ Academic training level } \\
\hline $\mathrm{R} 1$ & 8 & 7.92 \\
\hline $\mathrm{R} 2$ & 29 & 28.71 \\
\hline R3 & 28 & 27.72 \\
\hline R4 & 18 & 17.82 \\
\hline R5 & 18 & 17.82 \\
\hline \multicolumn{3}{|l|}{ Center level of training } \\
\hline University hospital & 20 & 19.80 \\
\hline Secondary hospital & 36 & 35.64 \\
\hline Tertiary hospital & 45 & 44.55 \\
\hline \multicolumn{3}{|l|}{ Place of training } \\
\hline Central region & 28 & 27.72 \\
\hline Eastern region & 32 & 31.68 \\
\hline Western region & 27 & 26.73 \\
\hline Southern region & 14 & 13.06 \\
\hline
\end{tabular}

Table 2 Impact of the COVID-19 pandemic on the frequency of various training activities per week 


\begin{tabular}{|llllllllllllll|l|}
\hline & \multicolumn{3}{c}{ Before COVID-19 } & \multicolumn{4}{c}{ During COVID-19 } & \multicolumn{3}{cl}{ t-test } & \multicolumn{3}{l|}{ Cohen's d } \\
\hline & Mean & SD & Min & Max & Mean & SD & Min & Max & t(100) & P & d & Magnitude \\
\hline Outpatient clinic number & 2.98 & 1.42 & 0 & 7 & 1.19 & 1.44 & 0 & 7 & 11.39 & $<0.001$ & 1.13 & Large \\
\hline Elective OR number & 3.09 & 0.28 & 1 & 24 & 0.35 & 0.85 & 0 & 6 & 9.14 & $<0.001$ & 0.91 & Large \\
\hline Office-based procedures number & 4.23 & 4.45 & 0 & 24 & 1.20 & 3.32 & 0 & 24 & 7.99 & $<0.001$ & 0.79 & Moderate \\
\hline Hospital on calls frequency & 1.03 & 1.23 & 0 & 4 & 0.80 & 1.16 & 0 & 4 & 2.34 & 0.021 & 0.23 & Mild \\
\hline Home on calls frequency & 1.55 & 1.44 & 0 & 4 & 1.6 & 1.43 & 0 & 4 & -0.49 & 0.690 & 0.05 & Nonsignificant \\
\hline Consultations number & 6.35 & 4.90 & 0 & 24 & 3.08 & 3.08 & 0 & 15 & 8.92 & $<0.001$ & 0.89 & Large \\
\hline Average working hours per week & 52.92 & 30.43 & 8 & 272 & 30.26 & 28.92 & 0 & 188 & 11.28 & $<0.001$ & 1.15 & Large \\
\hline Average working hours per day & 9.53 & 3.58 & 2 & 20 & 5.86 & 3.13 & 0 & 10 & 9.67 & $<0.001$ & 0.96 & Large \\
\hline
\end{tabular}

Table 3 Influence of the COVID-19 pandemic on academic activities in relation to level of training program

\begin{tabular}{|c|c|c|c|c|c|c|c|c|c|c|c|}
\hline & \multicolumn{4}{|c|}{ Junior Trainees } & \multicolumn{7}{|c|}{ Senior Trainees } \\
\hline & \multicolumn{2}{|l|}{ R1 } & \multicolumn{2}{|l|}{ R2 } & \multicolumn{2}{|l|}{ R3 } & \multicolumn{2}{|l|}{ R4 } & \multicolumn{2}{|l|}{ R5 } & \multirow[t]{2}{*}{ Total } \\
\hline & $N=8$ & $7.92 \%$ & $N=29$ & $28.71 \%$ & $N=28$ & $27.72 \%$ & $N=18$ & $17.82 \%$ & $N=18$ & $17.82 \%$ & \\
\hline \multicolumn{12}{|c|}{ Clinical activities were resumed in spite of COVID-19 } \\
\hline Yes & 4 & 6.67 & 13 & 21.67 & 14 & 23.33 & 16 & 26.67 & 13 & 21.67 & 60 \\
\hline No & 4 & 9.76 & 16 & 39.02 & 14 & 34.15 & 2 & 4.88 & 5 & 12.20 & 41 \\
\hline \multicolumn{12}{|c|}{ Participation in a research project related to COVID-19 } \\
\hline Yes & 4 & 25.00 & 5 & 31.25 & 2 & 12.50 & 3 & 18.75 & 2 & 12.50 & 16 \\
\hline No & 4 & 4.71 & 24 & 28.24 & 26 & 30.59 & 15 & 17.65 & 16 & 18.82 & 85 \\
\hline \multicolumn{12}{|c|}{ Involving with COVID-19 patients as a frontline physician } \\
\hline Yes & 6 & 20.00 & 13 & 43.33 & 7 & 23.33 & 2 & 6.67 & 2 & 6.67 & 30 \\
\hline No & 2 & 2.82 & 16 & 22.54 & 21 & 29.58 & 16 & 22.54 & 16 & 22.54 & 71 \\
\hline \multicolumn{12}{|c|}{ Contacting with COVID-19 patients } \\
\hline Yes & 5 & 16.67 & 10 & 33.33 & 7 & 23.33 & 3 & 10.00 & 5 & 16.67 & 30 \\
\hline No & 3 & 4.23 & 19 & 26.76 & 21 & 29.58 & 15 & 21.13 & 13 & 18.31 & 71 \\
\hline \multicolumn{12}{|c|}{ Using telemedicine to follow up patients during COVID-19 } \\
\hline Yes & 3 & 4.69 & 20 & 31.25 & 16 & 25.00 & 11 & 17.19 & 14 & 21.88 & 64 \\
\hline No & 5 & 13.51 & 9 & 24.32 & 12 & 34.43 & 7 & 18.92 & 4 & 10.81 & 37 \\
\hline
\end{tabular}

Table 4: Summary of central tendencies of ENT trainees' attitude items' scores in relation to their training level 


\begin{tabular}{|c|c|c|c|c|c|c|c|c|c|c|c|c|c|c|}
\hline & \multicolumn{4}{|c|}{ Junior Trainees } & \multicolumn{6}{|c|}{ Senior Trainees } & \multicolumn{2}{|l|}{ Total } & \multicolumn{2}{|c|}{ ANOVA test } \\
\hline & R1 & & $\mathrm{R} 2$ & & R3 & & R4 & & R5 & & & & & \\
\hline & Mean & SD & Mean & SD & Mean & SD & Mean & SD & Mean & SD & Mean & SD & $\mathbf{F}$ & $\mathbf{P}$ \\
\hline $\begin{array}{l}\text { How do you rate } \\
\text { your training } \\
\text { program during } \\
\text { COVID-19? }\end{array}$ & 43.75 & 17.68 & 36.90 & 19.96 & 41.98 & 16.26 & 37.78 & 19.38 & 46.88 & 21.27 & 40.78 & 18.87 & 0.88 & 0.480 \\
\hline $\begin{array}{l}\text { How do you rate } \\
\text { your continuous } \\
\text { medical education } \\
\text { program during } \\
\text { CoVID-19? }\end{array}$ & 47.92 & 16.52 & 52.98 & 17.60 & 58.02 & 17.52 & 62.22 & 23.12 & 72.92 & 22.67 & 58.87 & 20.41 & 3.51 & 0.010 \\
\hline $\begin{array}{l}\text { How do you rate } \\
\text { your clinical } \\
\text { knowledge during } \\
\text { COVID-19? }\end{array}$ & 47.92 & 20.77 & 50.60 & 15.37 & 50.62 & 12.64 & 53.33 & 24.56 & 61.46 & 25.62 & 52.66 & 18.98 & 1.16 & 0.335 \\
\hline $\begin{array}{l}\text { How do you rate } \\
\text { your performance } \\
\text { in an emergency } \\
\text { during COVID-19? }\end{array}$ & 43.75 & 19.80 & 52.38 & 17.40 & 53.70 & 18.10 & 54.44 & 21.33 & 70.83 & 18.76 & 55.50 & 19.76 & 3.75 & 0.007 \\
\hline $\begin{array}{l}\text { How do you rate } \\
\text { your participation } \\
\text { in scientific } \\
\text { activities through a } \\
\text { smart learning } \\
\text { program during } \\
\text { coVID-19? }\end{array}$ & 60.42 & 25.10 & 55.36 & 26.47 & 60.49 & 21.26 & 71.11 & 24.77 & 78.13 & 18.97 & 63.65 & 24.44 & 2.93 & 0.025 \\
\hline $\begin{array}{l}\text { How do you rate } \\
\text { your attitude to } \\
\text { patients during } \\
\text { COVID-19? }\end{array}$ & 56.25 & 23.46 & 63.69 & 23.59 & 58.02 & 17.52 & 60.00 & 21.64 & 79.17 & 18.76 & 63.48 & 63.48 & 3.07 & 0.020 \\
\hline $\begin{array}{l}\text { How do you rate } \\
\text { yourself during } \\
\text { COVID-19 } \\
\text { compared to } \\
\text { yourself during } \\
\text { regular duty? }\end{array}$ & 37.50 & 19.42 & 45.24 & 19.42 & 45.06 & 15.89 & 53.33 & 26.87 & 62.50 & 26.18 & 48.76 & 22.57 & 2.66 & 0.038 \\
\hline
\end{tabular}

Score from 0 to 100

Table 5: Distribution of anxiety screening questions (GAD-7 questions) in relation to shifting to performing frontline duties instead of regular ENT training clinical duties 


\begin{tabular}{|c|c|c|c|c|c|c|c|c|}
\hline & \multicolumn{2}{|c|}{ COVID-19 related frontline clinical duties } & \multicolumn{2}{|c|}{$\begin{array}{l}\text { Regular otolaryngology training } \\
\text { clinical duties }\end{array}$} & \multirow[t]{2}{*}{ Total } & \multicolumn{3}{|c|}{ Chi-squared test } \\
\hline & $N=30$ & $\%$ & $N=71$ & $\%$ & & $x^{2}$ & df & $\mathbf{P}$ \\
\hline \multicolumn{5}{|c|}{ Do you experience excessive worry? } & & 1.044 & 1 & 0.307 \\
\hline Yes & 16 & 34.78 & 30 & 65.22 & 46 & & & \\
\hline No & 14 & 25.45 & 41 & 74.55 & 55 & & & \\
\hline \multicolumn{6}{|c|}{$\begin{array}{l}\text { Is your worry excessive in intensity, frequency, or amount of distress it } \\
\text { causes? }\end{array}$} & 0.110 & 1 & 0.740 \\
\hline Yes & 9 & 32.14 & 19 & 67.86 & 28 & & & \\
\hline No & 21 & 28.77 & 52 & 71.23 & 73 & & & \\
\hline \multicolumn{6}{|c|}{$\begin{array}{l}\text { Do you find it difficult to control the worry (or stop worrying) once it } \\
\text { starts? }\end{array}$} & 0.054 & 1 & 0.817 \\
\hline Yes & 10 & 31.25 & 22 & 68.75 & 32 & & & \\
\hline No & 20 & 28.99 & 49 & 71.01 & 69 & & & \\
\hline \multicolumn{6}{|c|}{$\begin{array}{l}\text { Do you worry excessively or uncontrollably about minor things such as being late for an } \\
\text { appointment, minor repairs, homework, etc.? }\end{array}$} & 0.809 & 1 & 0.368 \\
\hline Yes & 9 & 24.32 & 28 & 75.68 & 37 & & & \\
\hline No & 21 & 32.81 & 43 & 67.19 & 64 & & & \\
\hline
\end{tabular}

Table 6: Summary of central tendencies of training-related specific worries' items scores caused by the COVID-19 pandemic in relation to the otolaryngology residency program training level

\begin{tabular}{|c|c|c|c|c|c|c|c|c|c|c|c|c|c|c|}
\hline & \multicolumn{4}{|c|}{ Junior Trainees } & \multicolumn{6}{|c|}{ Senior Trainees } & \multicolumn{2}{|l|}{ Total } & \multicolumn{2}{|c|}{ ANOVA test } \\
\hline & R1 & & R2 & & R3 & & R4 & & R5 & & & & & \\
\hline & Mean & SD & Mean & SD & Mean & SD & Mean & SD & Mean & SD & Mean & SD & $F$ & $\mathbf{P}$ \\
\hline $\begin{array}{l}\text { Lack of social } \\
\text { support }\end{array}$ & 34.38 & 30.32 & 31.83 & 27.03 & 34.36 & 33.37 & 50.06 & 31.60 & 35.5 & 29.26 & 36.52 & 30.41 & 1.15 & 0.320 \\
\hline $\begin{array}{l}\text { Lack of rotation } \\
\text { plan }\end{array}$ & 70.5 & 25.11 & 64.28 & 31.50 & 63.39 & 30.68 & 81.29 & 23.41 & 61.44 & 38.45 & 67.02 & 30.99 & 1.07 & 0.378 \\
\hline $\begin{array}{l}\text { Lack of personal } \\
\text { experience }\end{array}$ & 67.13 & 29.18 & 72.48 & 23.81 & 44.32 & 31.93 & 72.24 & 27.67 & 48.06 & 33.65 & 59.97 & 31.33 & 4.92 & 0.001 \\
\hline $\begin{array}{l}\text { Lack of feedback } \\
\text { and guidance }\end{array}$ & 41.88 & 23.97 & 54.45 & 38.82 & 45.04 & 29.67 & 52.35 & 27.23 & 52 & 35.77 & 49.97 & 32.58 & 0.45 & 0.77 \\
\hline $\begin{array}{l}\text { Lack of } \\
\text { concentration on } \\
\text { tasks }\end{array}$ & 48.88 & 23.89 & 61.21 & 34.41 & 43.11 & 39.23 & 46.71 & 34.62 & 55.38 & 37.22 & 51.56 & 35.76 & 1.06 & 0.383 \\
\hline Lack of sleep & 27.5 & 31.09 & 31.69 & 28.81 & 25.75 & 28.03 & 28.24 & 25.02 & 32.44 & 33.98 & 29.17 & 28.59 & 0.21 & 0.931 \\
\hline $\begin{array}{l}\text { Delay of } \\
\text { graduation/rotation }\end{array}$ & 52.25 & 36.59 & 47 & 35.03 & 58.61 & 34.06 & 70.18 & 37.04 & 66.81 & 33.29 & 58.00 & 35.35 & 1.54 & 0.196 \\
\hline
\end{tabular}

Score from 0 to 100 